\title{
Seasonal population dynamics of the monogeneans Pseudorhabdosynochus coioidesis and $P$. serrani on wild versus cultured groupers in Daya Bay, South China Sea
}

\author{
Y. F. LUO ${ }^{1,2}$, T. B. YANG ${ }^{1, *}$ \\ ${ }^{1}$ School of Life Sciences, State Key Laboratory of Biocontrol, Sun Yat-sen University, Guangzhou, 510275, China, \\ E-mail: lssytb@mail.sysu.edu.cn; ${ }^{2}$ Department of Chemistry and Life Sciences, Gannan Normal University, \\ Ganzhou, 341000, China
}

\begin{abstract}
Summary
In this paper, seasonal samples of wild versus cultured groupers, Epinephelus spp., from Daya Bay, South China Sea were examined to survey the seasonality of two important species, Pseudorhabdosynochus coioidesis and $P$. serrani (Monogenea: Diplectanidae), and to analyze the interspecific relationships between these two parasites. Between April 2008 and January 2009, P. coioidesis and $P$. serrani were found to be parasitic only on E. coioides Hamilton during summer and winter in the natural waters of Daya Bay, exhibiting a high degree of host specificity, whereas they co-occurred and persisted on several species of hosts, such as E. coioides, E. bruneus Block and E. awoara Temminck \& Schlegel, in an experimental polyculture pond during several seasons. E. coioides is the main host for both of these two monogenean species. The overall prevalences and mean intensities of these two parasites on polycultured Epinephelus spp. showed the same pattern of seasonal fluctuations, with the maximum values during autumn, except for the overall prevalence of $P$. serrani, which reached its maximum values during summer and winter and the minimum values during spring and autumn. Prevalence and mean intensity were found to be related to host size. In the wild, medium-sized fishes harboured higher infections, whereas under cultured conditions the small-sized and large-sized fishes were more heavily infected. Simultaneous infections of $P$. coioidesis and $P$. serrani were common, and there was a significant positive interspecific correlation between these two parasites.
\end{abstract}

Keywords: population dynamics; Monogenea; Pseudorhabdosynochus coioidesis; Pseudorhabdosynochus serrani; Epinephelus; Daya Bay, South China Sea

\section{Introduction}

Groupers, Epinephelus spp., represent one of the most important resources targeted by coastal fisheries and aquaculture in Southeast Asian countries (Liao et al., 2001). The outbreak of diseases has been an impediment to their culture (Zeng, 2006; Do \& Phan, 2007). Deadly pathogens, including viruses, bacteria and parasites, have been reported (Fukuda et al., 1996; Leong, 1997; Cribb et al., 2002; Nagasawa \& Cruz-Lacierda, 2004; Yuki et al., 2008). Monogeneans are a group of pathogens which are difficult to eradicate in an open culture system (Leong, 1997). Consequently, investigations into their population dynamics are important for disease control and the maintenance of a healthy relationship between the cultured fish and their environment (Kabata, 1985). Ecological studies on monogeneans of fishes generally focused on single species of hosts in natural systems (e.g., Rawson \& Rogers, 1973; Gonzalez-Lanza \& Alvarez-Pellitero, 1982; Koskivaara et al., 1991; Mo, 1992; Van Damme \& Ollevier, 1994; Appleby, 1996; Winger et al., 2008) or laboratory experiments (Scott \& Anderson, 1984). It is, however, difficult to understand the impact of host susceptibility on infection dynamics between farmed and wild hosts.

A total of 45 species of Pseudorhabdosynochus Yamaguti, a taxon found mainly on the gills of Epinephelus spp., have been reported (Justine, 2007). Host specificity is generally considered an important feature for these species. It has been observed that several species of Pseudorhabdosynochus spp. can occur in the same aquaculture system or environment, e.g. 15 species on wild Epinephelus spp. in Daya Bay (Zeng, 2006), and thus the relationships between these species require clarification.

Pseudorhabdosynochus coioidesis $\mathrm{Bu}$ et al. and P. serrani (Yamaguti) Kritsky \& Beverley-Burton have a high host specificity (Bu et al., 1999; Yang et al., 2005) and fre- 
quently cause serious damage to Epinephelus spp. in captivity (Zeng, 2006; Do \& Phan, 2007). The groupers in Daya Bay $\left(23^{\circ} 25^{\prime} \mathrm{N}, 117^{\circ} 2^{\prime} \mathrm{E}\right)$, South China Sea, include common species, such as E. coioides Hamilton, E. awoara Temminck \& Schlegel, E. bruneus Bloch, E. quoyanus Valenciennes and E. bleekeri Vaillant, plus rarer species, such as E. fasciatomaculosus Peters, E. lanceolatus Bloch, E. malabaricus Bloch \& Schneider, E. areolatus Forsskål, E. chlorostigma Valenciennes, E. fasciatus Forsskål, E. fuscoguttatus Forsskål, E. macrospilos Bleeker, E. akaara Temminck \& Schlegel, E. longispinis Kner (syn. E. fario (Thunberg)) and Epinephelus sp. among others. Studies of the monogenean fauna of wild groupers in this bay (Zeng, 2006) have revealed that four species (E. coioides, E. fasciatus, E. macrospilos and E. bleekeri) and five species ( $E$. coioides, E. bruneus, E. fuscoguttatus, E. longispinis and $E$. bleekeri) harbour infections of $P$. coioidesis and $P$. serrani, respectively.

The aim of the present study was to survey the seasonality of the two most important species, $P$. coioidesis and $P$. serrani, of the gill monogenean communities of several groupers, E. coioides, E. awoara and E. bruneus, under wild versus polycultured conditions in Daya Bay, South China Sea, and to analyze the relationships between these two species when co-existing on these hosts.

\section{Materials and methods}

\section{Experimental design and host collection}

Epinephelus species were identified to species according to previous descriptions (Cheng \& Zhen, 1987; Heemstra \& Randall, 1993).

A 54,000 litre cement pond $\left(6 \times 6 \times 3 \mathrm{~m}^{3}\right)$ was set up at the Mariculture Research Centre, Guangdong Marine and Fishery Bureau at Ao'tou, Huizhou, Guangdong Province. The experimental pond was supplied with continuouslyflowing $\left(10 \mathrm{~m}^{3} / \mathrm{h}\right)$ sand-filtered sea water pumped from the bottom of an adjacent small estuary. This pond served as an experimental polyculture system for investigating the effect of host living conditions on infection by the parasites and for studying variations in host susceptibility under polyculture conditions.

In Daya Bay, the months of March to May are recognized as the spring season, summer extends from June to August, autumn occurs from September through to November and winter lasts from December to the following February. The research described here was carried out over a 10-month period, from April 2008 to January 2009. Samples of wild host fishes were collected monthly from Daya Bay using trap cages. Some of the captured fishes were immediately placed into the experimental pond, where they were polycultured over 25 days. Seasonal samples of the wild and cultured fish were examined at the end of each month between April 2008 and January 2009. A total of 211 individual fishes were kept in the experimental pond, with 35 specimens of each of the five main Epinephelus spp. (E. coioides, E. awoara, E. bruneus, E. quoyanus and E. bleekeri). Six individuals of the four rare Epinephelus spp.
(E. fasciatus, E. fuscoguttatus, E. areolatus and Epinephelus sp.) and other 2 potential host species, such as Cephalopholis pachycentron Valenciennes (Serranidae: Epinephelinae) and Sciaenops ocellatus Linnaeus (Sciaenidae) were also included. Samples of fish were removed monthly for parasite examination and were immediately replaced by the same numbers of fishes of the same species. Small individuals (total length $<10 \mathrm{~cm}$ ) were isolated in two net cages in the experimental pond to avoid predation. The salinity and water surface temperature were measured daily.

The host fishes were divided into three size groups based on their body length, small $(<20 \mathrm{~cm})$, medium $(20-24$ $\mathrm{cm})$ and large $(>24 \mathrm{~cm})$ to see whether any relationship existed between fish length and the infection levels of $P$. coioidesis and $P$. serrani.

Parasite examination

Sample fish were sacrificed by pithing, a slaughtering technique in which the brain of the animal is scrambled with a tool inserted through the foramen magnum, for parasite examination. Total length and body weight were determined for each individual fish. The gills were excised immediately after death and placed in separate Petri dishes containing seawater. The epithelial linings of the gill filaments were scraped with a needle and the scrapings were collected in a beaker filled with seawater. The contents were then stirred, allowed to settle and the supernatant decanted. This procedure was repeated until a clear suspension was obtained. Sediments were examined under a dissecting microscope and parasites in them were placed on a slide with the fixative ammonium picrateglycerine. The identity of specimens of $P$. coioidesis and $P$. serrani on each slide was confirmed by microscopical examination (using an Olympus BX41), and data on their presence were recorded in a log. Different species were distinguished by their morphology and measurements of the haptoral sclerites and male copulatory organs, as previously proposed by $\mathrm{Bu}$ et al. (1999), Kritsky and Beverley-Burton (1986), Yang et al. (2005) and Justine (2005, 2007, 2008).

Statistical analyses

Prevalence, intensity, mean intensity and abundance were calculated following Margolis et al. (1982) and using the positive association coefficient of Legendre \& Legendre (1983). The mean intensities of parasites, for different seasons and for the entire sampling time, were determined for both experimentally polycultured and wild hosts. The chi-squared test was used to test seasonal differences in prevalence. A one-way analysis of variance (ANOVA) (Bryman \& Duncan, 1997) was employed to evaluate differences in the abundances and mean intensities of $P$. coioidesis and P. serrani on E. coioides, E. awoara and E. bruneus and in pooled seasonal data. Spearman's rho correlation analyses were used to test the interspecific correlation between the two species of parasites in cases of concurrent infections. All statistical analyses were executed using SPSS 11.5 (SPSS Inc., Chicago, Illinois) at a significance level of 0.05 . 


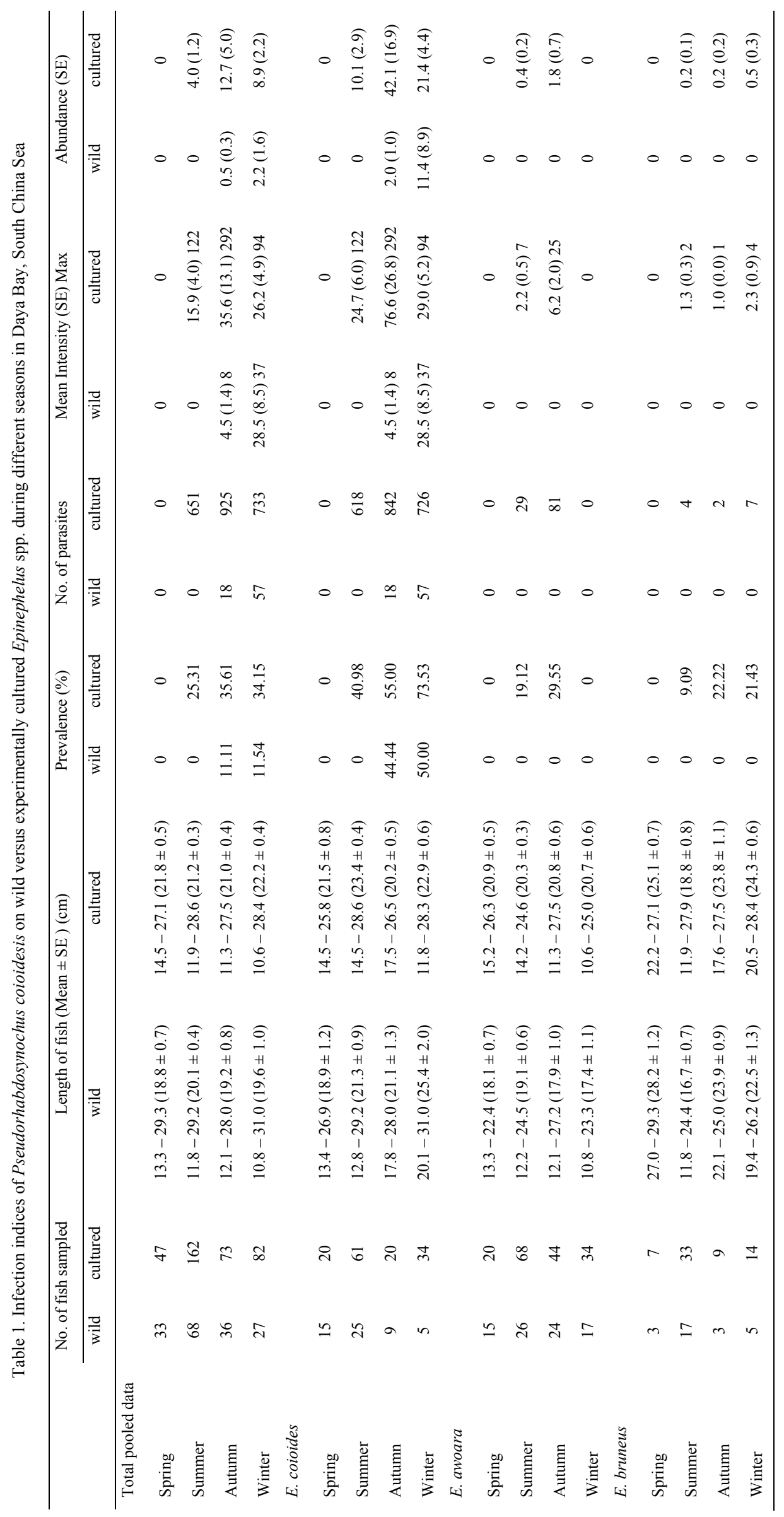




\section{Results}

Seasonal variations in populations of $P$. coioidesis and $P$. serrani

In this study, a total of 84,814 specimens of diplectanid monogeneans belonging to nine species (one Diplectanum and eight Pseudorhabdosynochus species) were found infecting wild and cultured Epinephelus spp. Among them 2,384 and 1,942 individuals were $P$. coioidesis and $P$. serrani, respectively, which were evidently the dominant species during autumn and winter in Daya Bay (Tables 1 and 2). and 2). Among these host species, E. coioides, E. awoara and $E$. bruneus played an important role in population dynamics of the two species of monogeneans. E. coioides exhibited the highest values of prevalence and mean intensity/abundance for both $P$. coioidesis and $P$. serrani, followed by E. awoara and E. bruneus for P. coioidesis and $P$. serrani, respectively (Tables 1 and 2). No specimens or low infection levels of the two parasites were found on the individuals of other Epinephelus spp. C. pachycentron and $S$. ocellatus were uninfected by both parasites during the sampling period. The overall prevalence of $P$. coioidesis and mean intensity of both $P$. coioidesis and $P$. serrani at

Table 2. Infection indices of Pseudorhabdosynochus serrani on wild versus experimentally cultured Epinephelus spp. during different seasons in Daya Bay, South China Sea

\begin{tabular}{|c|c|c|c|c|c|c|c|c|}
\hline & \multicolumn{2}{|c|}{ Prevalence (\%) } & \multicolumn{2}{|c|}{ No. of parasites } & \multicolumn{2}{|c|}{ Mean Intensity (SE) Max } & \multicolumn{2}{|c|}{ Abundance (SE) } \\
\hline & wild & cultured & wild & cultured & wild & cultured & wild & cultured \\
\hline \multicolumn{9}{|c|}{ Total pooled data } \\
\hline Spring & 0 & 0 & 0 & 0 & 0 & 0 & 0 & 0 \\
\hline Summer & 0 & 32.72 & 0 & 602 & 0 & $11.4(1.6) 45$ & 0 & $3.7(0.7)$ \\
\hline Autumn & 8.33 & 26.03 & 32 & 537 & $10.7(4.1) 18$ & $28.3(7.8) 122$ & $0.9(0.6)$ & $7.4(2.5)$ \\
\hline Winter & 7.69 & 39.02 & 59 & 712 & $19.7(2.5) 32$ & $22.3(4.6) 119$ & $2.2(1.6)$ & $8.7(2.1)$ \\
\hline \multicolumn{9}{|c|}{ E. coioides } \\
\hline Spring & 0 & 0 & 0 & 0 & 0 & 0 & 0 & 0 \\
\hline Summer & 0 & 55.74 & 0 & 469 & 0 & $13.8(2.0) 45$ & 0 & $7.7(1.4)$ \\
\hline Autumn & 33.33 & 55.00 & 32 & 472 & $10.7(4.1) 18$ & $42.9(11.2) 122$ & $3.6(2.1)$ & $23.6(7.8)$ \\
\hline Winter & 60.00 & 79.41 & 59 & 698 & $19.7(2.5) 32$ & $26.9(5.2) 119$ & $11.8(8.6)$ & $20.5(4.5)$ \\
\hline \multicolumn{9}{|c|}{ E. awoara } \\
\hline Spring & 0 & 0 & 0 & 0 & 0 & 0 & 0 & 0 \\
\hline Summer & 0 & 13.24 & 0 & 46 & 0 & $5.1(1.4) 14$ & 0 & $0.7(0.3)$ \\
\hline Autumn & 0 & 11.36 & 0 & 10 & 0 & $2.0(0.6) 4$ & 0 & $0.2(0.1)$ \\
\hline Winter & 0 & 11.76 & 0 & 6 & 0 & $1.5(0.5) 3$ & 0 & $0.2(0.1)$ \\
\hline \multicolumn{9}{|c|}{ E. bruneus } \\
\hline Spring & 0 & 0 & 0 & 0 & 0 & 0 & 0 & 0 \\
\hline Summer & 0 & 30.30 & 0 & 87 & 0 & $8.7(4.2) 44$ & 0 & $2.6(1.4)$ \\
\hline Autumn & 0 & 33.33 & 0 & 55 & 0 & $18.3(12.6) 43$ & 0 & $6.1(4.7)$ \\
\hline Winter & 0 & 14.29 & 0 & 8 & 0 & $4.0(3.0) 7$ & 0 & $0.6(0.5)$ \\
\hline
\end{tabular}

In the wild, E. coioides was found to be infected with $P$. coioidesis and $P$. serrani during autumn and winter in Daya Bay, whereas no specimens of these two parasites were collected from the other wild species of Epinephelus during the sampling period (Tables 1 and 2). Seasonal prevalence, mean intensity and abundance of $P$. coioidesis or $P$. serrani on wild $E$. coioides were significantly different (Table 3).

Under polycultured conditions, however, a total of seven Epinephelus species (E. coioides, E. awoara, E. bruneus, E. quoyanus, E. fasciatomaculosus, E. fuscoguttatus and $E$. bleekeri) were infected by $P$. coioidesis and nine species of Epinephelus (E. coioides, E. bruneus, E. awoara, E. quoyanus, E. fasciatomaculosus, E. areolatus, E. fuscoguttatus, E. fasciatus and Epinephelus sp.) by P. serrani (Tables 1 the component population level showed the same pattern of seasonal fluctuations, with a peak of infection occurring in autumn, whereas the maximum values of the overall prevalence of $P$. serrani were found during summer and winter, and the minimum values occurred during spring and autumn (Fig. 1). There were significant seasonal differences in both the overall prevalence and abundance of P. coioidesis and P. serrani (Table 3).

On polycultured $E$. coioides, the prevalence of $P$. coioidesis increased during summer and autumn, and reached a peak in winter (Fig. 1). The prevalence of P. serrani in summer levelled out during the autumn and likewise attained its highest values in winter (Fig. 1). In the case of mean intensity, in both parasite species it reached a peak in autumn (Fig. 1). The mean intensity and abundance of both 
a

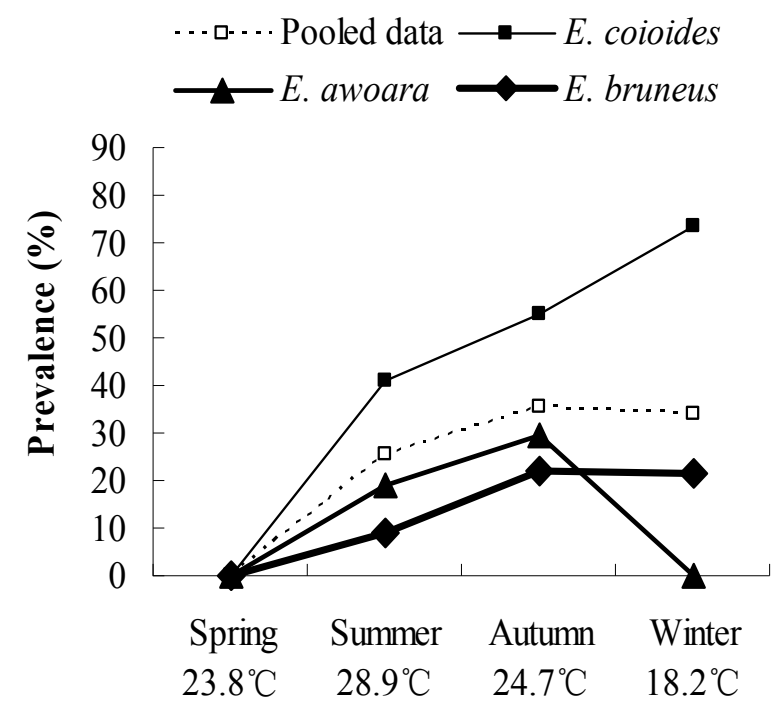

a

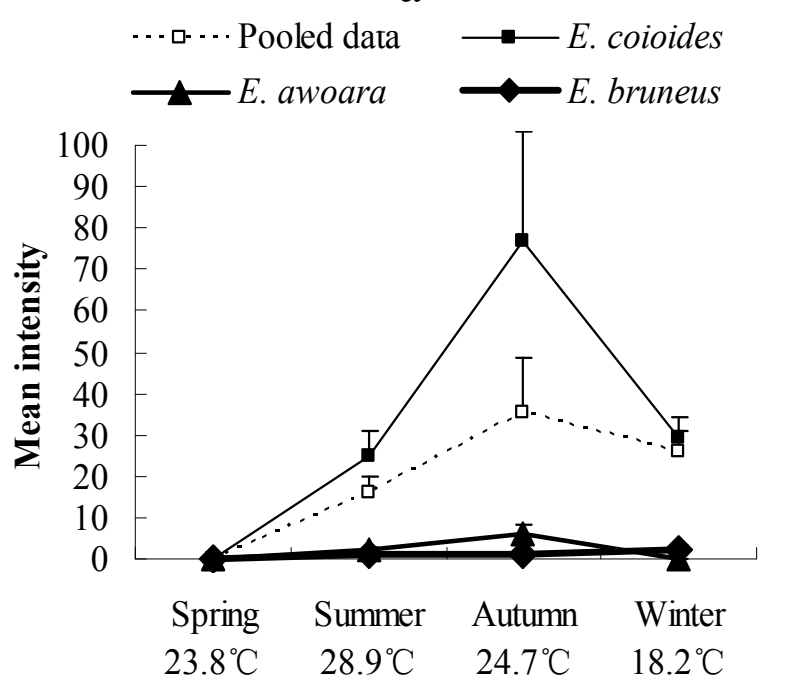

b

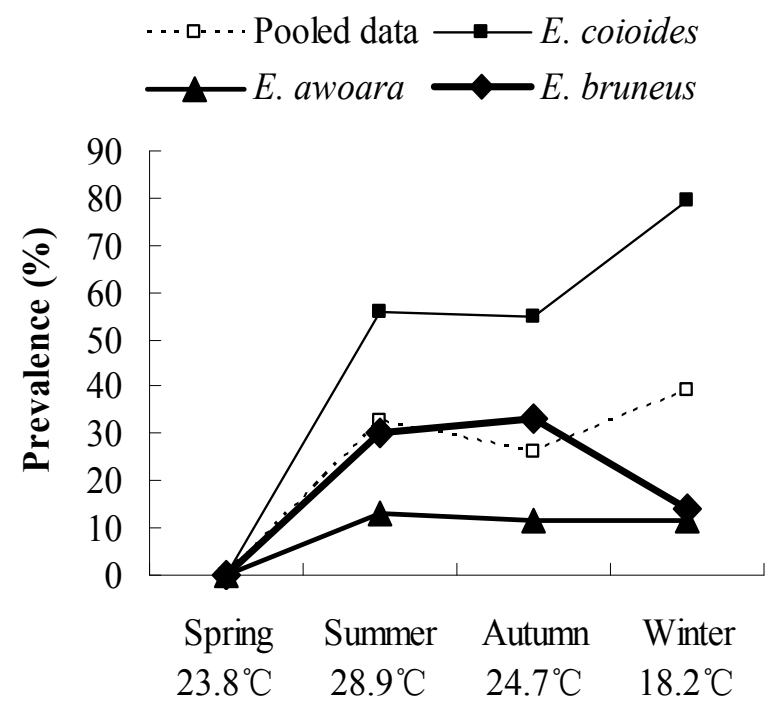

b

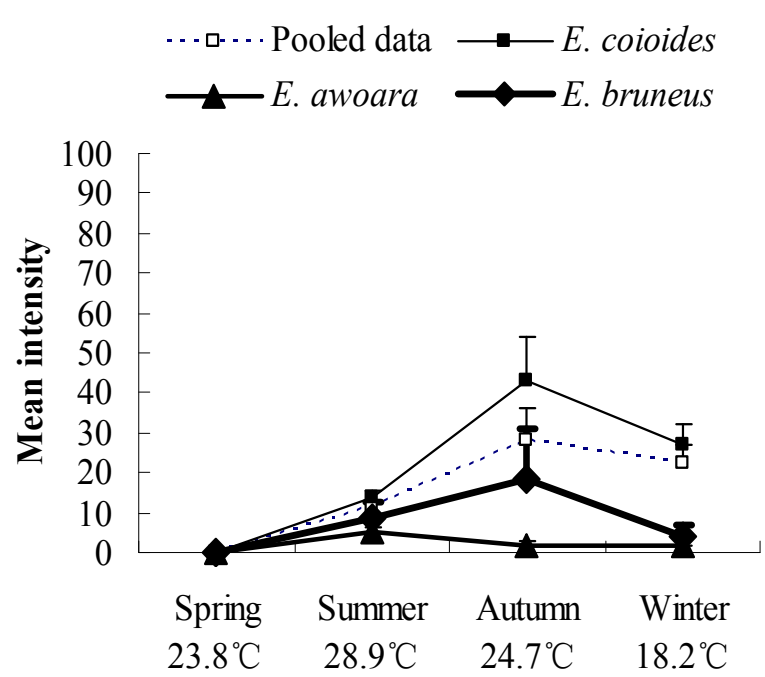

Fig. 1. Seasonal prevalences and mean intensities of Pseudorhabdosynochus coioidesis (a) and P. serrani (b) on the polycultured Epinephelus spp. in Daya Bay, South China Sea

$P$. coioidesis and $P$. serrani exhibited significant seasonal differences, whereas their prevalence did not differ significantly between seasons (Table 3 ).

On polycultured E. awoara, the infection levels of $P$. coioidesis were higher than those of $P$. serrani. Values of both prevalence and mean intensity of $P$. coioidesis reached their highest levels during autumn, but in the case of $P$. serrani during summer (Fig. 1). No infection with these two species of monogeneans was found during the spring and winter (Tables 1 and 2). Seasonal differences in the prevalence of $P$. coioidesis and $P$. serrani were significant, but not those of their mean intensity (Table 3 ).

On polycultured E. bruneus, prevalence values of $P$. coioidesis attained their highest values in autumn, whereas the highest values for mean intensity were found during winter. The prevalence of $P$. serrani reached their maximum values during summer and autumn and their minimum values during spring and winter; mean intensity peaked in autumn (Fig. 1). Significant seasonal differences in the mean intensity and abundance of both monogenean species were also detected (Table 3 ).

Prevalences and mean intensities of $P$. coioidesis and $P$. serrani in relation to host size

In the wild, there was the same pattern of fluctuations in the prevalence and mean intensity of $P$. coioidesis and $P$. 
a

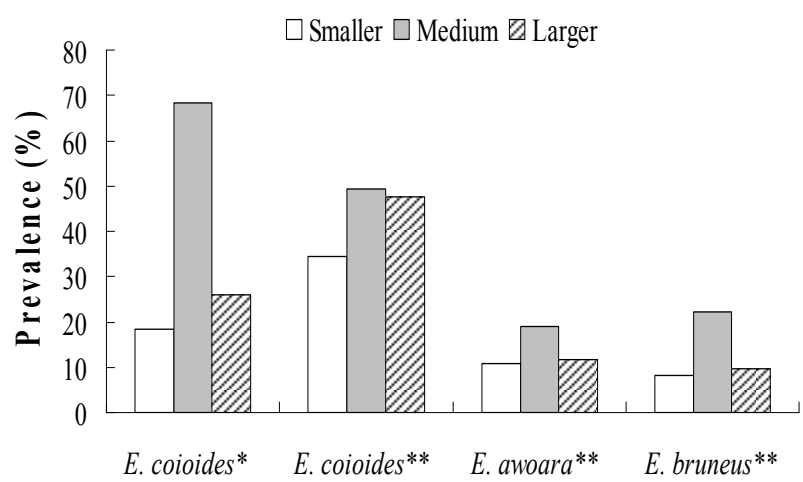

a

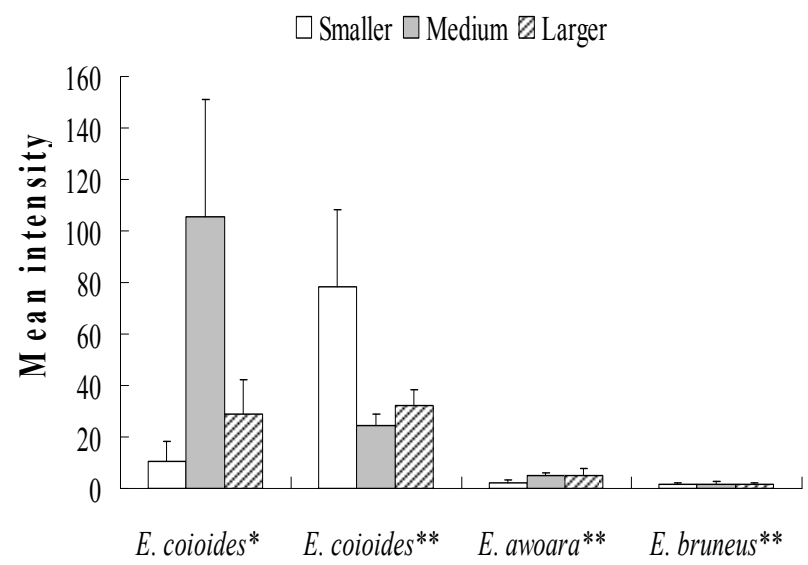

$\mathrm{b}$

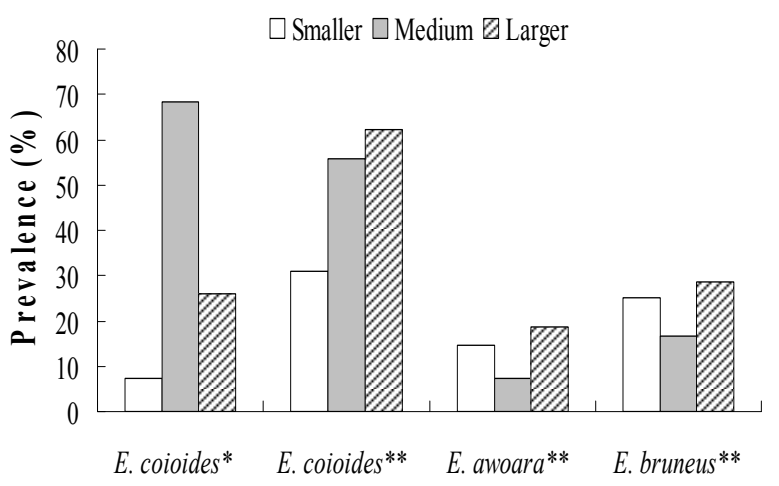

b

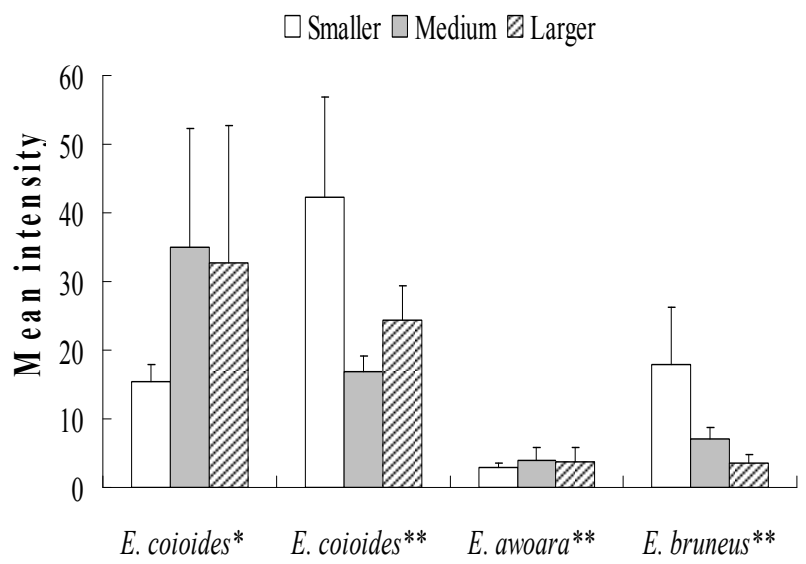

Fig. 2. Comparative prevalences and mean intensities of Pseudorhabdosynochus coioidesis (a) and P. serrani (b) in different length group of Epinephelus spp. under wild (*) and polycultured (**) conditions in Daya Bay, South China Sea

serrani on specimens of $E$. coioides of different sizes, with the highest values recorded from hosts of medium size (20 $-24 \mathrm{~cm}$ in body length), whereas the lowest values were for small sized fish $(<20 \mathrm{~cm})$ (Fig. 2).

Under polycultured conditions, the highest prevalence of $P$. coioidesis on E. coioides, E. awoara and E. bruneus was also found in the medium size group and the lowest in the small size group (Fig. 2). The highest prevalence of $P$. serrani on $E$. coioides was observed in the large size group and the lowest in the small size group, whereas that on $E$. awoara and E. bruneus was detected in the large size group and the lowest in the medium size group (Fig. 2). The highest mean intensity of $P$. coioidesis and $P$. serrani on $E$. coioides was recorded for the small size group and the lowest for the medium size group, but the mean intensities of these two parasites on E. awoara of the medium and large size groups exhibited the similar values as those for the small size group (Fig. 2). The mean intensity of $P$. coioidesis ranged from only 1.5 to 1.8 in E. bruneus in the case of all three size group, whereas that of $P$. serrani in the different size groups ranged from 3.5 to 18.0 , with the highest value in the small size group and the lowest in the large size group (Fig. 2).

Table 4. Intensities of Pseudorhabdosynochus coioidesis and $P$. serrani on cultured Epinephelus spp. in monospecific versus concurrent infections

\begin{tabular}{ccccc}
\hline Infection state & \multicolumn{2}{c}{ Monospecific infections } & \multicolumn{2}{c}{ Concurrent infections } \\
\cline { 2 - 5 } Parasites & P. coioidesis & P. serrani & P. coioidesis & $P$. serrani \\
& & & & \\
\hline Intensity & $1-68$ & $1-43$ & $1-292$ & $1-103$ \\
Mean Intensity & $6.3(2.2)$ & $7.4(1.3)$ & $33.4(6.0)$ & $24.6(3.3)$ \\
(SD) & & & & \\
\hline
\end{tabular}


Interspecific relationships between $P$. coioidesis and $P$. serrani

A positive association coefficient $(\mathrm{V}=0.48>0)$ was calculated for these two species of parasites based on data from their occurrence on polycultured hosts, with 63 concurrent infections of $P$. coioidesis and $P$. serrani, 34 monospecific $P$. coioidesis infections, 43 monospecific $P$. serrani infections and 224 without any infection. The positive associations between them were statistically significant $\left(\chi^{2}=82.13>x_{0.05}^{2}=3.84\right)$. Additionally, the mean intensities of both species in monospecific infections were less than those in concurrent infections (Table 4). In the case of concurrent infections on the gills, a Spearman correlation analyses of the intensities of the two parasite species on each host individual revealed a significant positive interspecific correlation $(r=0.49, \mathrm{n}=63, P=0.00)$.

\section{Discussion}

Pseudorhabdosynochus spp. represent a group of gill monogeneans on groupers (Justine, 2007), which cause respiratory problems, dark skin, a swollen operculum and mortality (Do \& Phan, 2007). Many species occur on cultured fishes of considerable economic importance (Nash et al., 1987; Leong \& Wong, 1990; Leong, 1994). P. coioidesis and $P$. serrani occurred in heavy infections on cultured $E$. coioides (Leong \& Wong, 1990; Zeng, 2006). The diseases caused by these two parasites are present between summer and winter (mostly between October and December) and mainly affect small fish of less than $200 \mathrm{~g}$ in weight in Southeast Asian waters (Zeng, 2006; Do \& Phan, 2007).

In this study, $P$. coioidesis and $P$. serrani were found only on $E$. coioides in autumn and winter during the sampling period in the natural waters of Daya Bay, whereas they cooccurred and persisted on several species of hosts under polycultured conditions throughout several seasons, although E. coioides was still the main host of the two suprapopulations. This suggests that there exists a stable parasite-host association between these two monogeneans and E. coioides and that these parasites have the ability to either infect $E$. coioides or to switch from it to other related hosts, such as E. awoara and E. bruneus. This surely represents a constant threat to the culture of several suitable species of Epinephelus. Similar results were observed for gyrodactylid (Rawson \& Rogers, 1973; Blazek et al., 2008) and benedeniine (Whittington \& Horton, 1996; Ernst \& Whittington, 2001) monogeneans. Host switching could be considered as a part of the process of monogenean dissemination (Kearn, 1994). A high abundance and population growth may favour a change of host. Mo (1997) observed a single Gyrodactylus aphyae and two specimens of G. macronychus parasitizing trout (Salmo trutta) in an area with a high gyrodactylid abundance on minnow. Similarly, Bakke et al. (1990, 1992), Bakke and Sharp (1990) and Soleng and Bakke (1998) observed a significant proportion of gyrodactylids to change host species under experimental conditions.

Specificity is determined as the host range width, i.e., the number of host species infected by a population of a single parasite species (Lymbery, 1989). Poulin (1992) noted that the number of known hosts is not an ideal measure of a parasite's host specificity, because reported hosts may not actually be suitable for parasite reproduction. Moreover, King and Cable (2007) stated that host specificity can never be presumed unless it has been tested experimentally. The present study supports the notion that the host specificity of $P$. coioidesis and $P$. serrani is in many cases strict. Consequently, we consider that the apparent host specificity of these two species found in this study needs to be treated with some degree of caution. Under conditions more suitable for infrapopulational growth, they perhaps exhibit more generalized host preferences. It is still not known whether monogenean infrapopulational growth is reduced by unsuitable water temperature, enhanced immunity or some other reason. It is known that the infrapopulational growth and infection duration of monogeneans often differ between related host species (e.g., Mo, 1997; Boeger et al., 2005; Moen \& Stockwell, 2006; Olstad et al., 2007), and the chemical structure of the epidermis and mucus of related fish can differ substantially (Buchmann \& Uldal, 1997). This may explain different abundances of $P$. coioidesis and $P$. serrani on E. coioides, E. awoara and E. bruneus in the present study. Sympatric fish hosts unsuitable for parasite reproduction could, on the other hand, be used as transient hosts (Bakke et al., 2002). Nonetheless, we found it likely that $P$. coioidesis can occur at least on six Epinephelus species (E. coioides, E. awoara, E. bruneus, E. quoyanus, E. fuscoguttatus and E. bleekeri) and that $P$. serrani can infect eight species (E. coioides, E. bruneus, E. awoara, E. quoyanus, E. areolatus, E. fuscoguttatus, E. fasciatus and Epinephelus sp.). Indeed, in addition to those listed above, $P$. coioidesis has also been found on $E$. areolatus, E. merra and E. fasciatus (see Bu et al., 1999; Hinsinger \& Justine, 2006) and P. serrani on E. longispinis and Serranus sp. (see Yamaguti, 1953; Zeng, 2006).

In the present study, although other species of Epinephelus, such as E. awoara and E. bruneus, could host the two species of parasites under polycultured conditions, we consider they are not natural hosts for these two species of monogeneans in the regular waters of Daya Bay, because neither were infected in the wild and had only very low infections in the polyculure system. Nevertheless, $E$. coioides under polycultured conditions is shown to increase their susceptibility to these two species of parasite. King and Cable (2007) observed that Gyrodactylus turnbulli switched readily to related host species under experimental conditions, whereas no such host changes were recorded under natural conditions where these hosts form multispecies shoals (Cable et al., 2005). Consequently, care should be taken when transferring $E$. coioides to a cultured system for Epinephelus spp., as reported for Gyrodactylus salaris Malmberg on salmons (Soleng \& Bakke, 1998, 2001).

Seasonal fluctuations in infections of monogeneans have previously been reported (e.g., Mo, 1992; Van Damme \& Ollevier, 1994; Appleby, 1996; West \& Roubal, 1998; 
Winger et al., 2008) which were due to the different responses of the parasites to seasonal variations in complex environments (Koskivaara, 1992). Temperature has been regarded as an important factor for controlling the rates of reproduction and survival of monogeneans (Scott \& Nokes, 1984; Jansen \& Bakke, 1991; Bakke et al., 2007; Winger et al., 2008). Some species of monogeneans tend to reproduce at a faster rate at higher water temperatures, whereas others prefer cool water temperatures (Hanzelová \& Žitňan, 1985; Pojmaňska, 1994; Ötürk \& Altunel, 2006). In Daya Bay, the water temperature varied during the sampling period. Evident seasonality was found in the infection patterns of both $P$. coioidesis and $P$. serrani. In the wild infections of $P$. coioidesis and $P$. serrani were found during autumn and winter. Under polycultured conditions no specimen of Epinephelus spp. was found to be infected with these two parasites during the sampling months of spring, and their infection levels were also low during summer, whereas a high prevalence and mean intensity occurred in autumn and early winter. This was probably due to the preference of the two species of monogeneans for cool water, on one hand, and the reduced immune response of the host to parasitic infection at lower temperature, on the other. Therefore, some necessary measures need to be taken to prevent the parasitic diseases from autumn to winter.

In this study, the prevalence and mean intensity of infection were found to be related to different size groups of the host. In the wild, the medium sized fishes were more heavily infected. The present finding agrees with that of Golder et al. (1987) in that, under cultured conditions, the rate of infection was greater in smaller and larger sized fishes than in the medium size group. This was probably because the smaller sized fishes have a lower immune response to the parasites, whereas the enhanced activity of the larger fish resulted in frequent contact between susceptible hosts which can harbour a greater number of parasites without harm.

Species of monogeneans on the same hosts exhibiting a weak positive interspecific correlation have been reported previously. These include Dactylogyrus spp. parasitizing Rutilus rutilus (see Koskivaara, 1992), microcotylids infecting Mugil cephalus (see Ei Hafidi et al., 1998) and Polylabris mamaevi and Tetrancistrum nebulosi on Siganus fuscescens (see Yang et al., 2006), but such a relationship was often statistically insignificant. However, in the present study, there was a significant positive interspecific correlation between $P$. coioidesis and $P$. serrani on Epinephelus spp. in Daya Bay. Similar results have also been observed for Protopolystoma fissilis and P. simplicis present sympatrically on the toad Xenopus wittei in Rwanda (Jackson et al., 2001). The 'aggregation model of coexistence' postulates that, if species (using the same type of resource) are distributed in such a way that interspecific aggregation is reduced relative to intraspecific aggregation, species coexistence is facilitated. Moreover, it has been confirmed that there is no overlap in the use of microhabitats for some monogeneans on the same host (Yang et al., 2006).

\section{Acknowledgements}

This research was financially supported by National Natural Science Foundation of China (No. 30771659). We would like to thank Wang Yunxin and Zhang Haifa in the Mariculture Research Center, Guangdong Marine and Fishery Bureau at Ao'tou, Huizhou, Guangdong Province for their kind help during the experiment.

\section{References}

ApPleBY, C. (1996): Population dynamics of Gyrodactylus sp. (Monogenea) infecting the sand goby in the Oslo Fjord, Norway. J. Fish Biol., 49: $402-410$

BAKKe, T. A., JANSEN, P. A., Brabrand, A. (1990): Susceptibility and resistance of brook lamprey, Lampetra planeri (Bloch), roach, Rutilus rutilus (L.) and perch, Perca fluviatilis L. to Gyrodactylus salaris Malmberg (Monogenea). Fauna Norv., Ser. A, 11: 23 - 26

BAKKe, T. A., Sharp, L. A. (1990): Susceptibility and resistance of minnow, Phoxinus phoxinus (L.) to Gyrodactylus salaris Malmberg, 1957 (Monogenea) under laboratory conditions. Fauna Norv., Ser. A, 11: $51-55$

BAKKe, T. A., HARris, P. D., JANSEN, P. A., HANSEN, L. P. (1992): Host specificity and dispersal strategy in gyrodactylid monogeneans, with particular reference to Gyrodactylus salaris (Platyhelminthes, Monogenea). Dis. Aquat. Org., 13: $63-74$

BAKKe, T. A., HARris, P. D., CABle, J. (2002): Host specificity dynamics: observation on gyrodactylid monogeneans. Int. J. Parasitol., 32: $281-308$

BAKKe, T. A., CABle, J., HARris, P. D. (2007): The biology of gyrodactylid monogeneans: the "Russian - doll killers". Adv. Parasitol., 64: $161-376$

BlazeK, R. D., Bagge, A., Valtonen, E. T. (2008): Monogenean assemblages and the apparent transmission capability of monogeneans between related fish species: an experimental study. Parasitol. Res., 102: 1359 - 1366

Boeger, W. A., Kritsky, D. C., PIE, M. R., Engers, K. B. (2005): Mode of transmission, host switching, and escape from the red queen by viviparous gyrodactylids (Monogenoidea). J. Parasitol., 91: 1000 - 1007

BRYMAN, A., DUNCAN, C. (1997): Quantitative data analysis with SPSS for Windows. London and New York, Routledge Bu, S. S. H., LeOng, T. S., Wong, S. Y., WoO, Y. S. N., FoO, R. W. T. (1999): Three diplectanid monogeneans from marine finfish (Epinephelus spp.) in the Far East. $J$. Helminthol., 73: $301-312$

BuCHMANN, K., ULDAL, A. (1997): Gyrodactylus derjavini infections in four salmonids: comparative host susceptibility and site selection of parasites. Dis. Aquat. Org., 28: 201 $-209$

Cable, J., Van Oosterhout, C., Barson, N., Harris, P. D. (2005): Gyrodactylus pictae n. sp. (Monogenea: Gyrodactylidae) from the Trinidadian swamp guppy Poecilia picta Regan, with a discussion on species of Gyrodactylus von Nordmann, 1832 and their poecilid hosts. Syst. Parasitol., 60: 159 - 164 
CHENG, Q. T., ZHEN, B. S. (1987): Systematic Synopsis of Chinese Fishes., Beijing, Science Press, 1458 pp.

CribB, T. H., Bray, R. A., Wright, T., Pichelin, S. (2002): The trematodes of groupers (Seranidae: Epinephelinae): knowledge, nature and evolution. Parasitology, 124: $23-42$

Do T. H., Phan, V. U. (2007): Monogenean disease in cultured grouper (Epinephelus spp.) and snapper (Lutjanus argentimaculatus) in Khanh Hoa province, Vietnam. Aquacul. Asia, 12: $40-42$

Ei Hafidi, F., Berrada-Rkhami, O., Benazzou, T., GARION, C. (1998): Microhabitat distribution and coexistence of Microcotylidae (Monogenea) on the gills of the striped mullet Mugil cephalus: Chance or competition? Parasitol. Res., 84: 315 - 320

ERnSt, I., WhitTington, I. D. (2001): Experimental susceptibility of some reef fish species to Benedenia lutjani (Monogenea: Capsalidae), a parasite of Lutjanus carponotatus (Pisces: Lutjanidae). Parasitol. Res., 87: 345 - 348

Fukuda, Y., NGuYen, H. D., Furuhashi, M., NAKai, T. (1996): Mass mortality of cultured sevenband grouper, Epinephelus septemfasciatus, associated with viral nervous necrosis. Fish Pathol., 31: $165-170$

Golder, M. I., ChNDRA, K. J., RAhMAn, A. K. A. (1987): Helminth parasitism in Nandus nandus (Hamilton). Bangladesh J. Fish, 10: 11 - 12

Gonzalez-Lanza, C., Alvarez-Pellitero, P. (1982): Description and population dynamics of Dactylogyrus legionensis n. sp. from Barbus bocagel Steind. J. Helminthol., 56: $263-273$

HANZELOVÁ, V., ŽITŇAN, R. (1985): Epizootiologic importance of the concurrent monogenean invasion in carp. $J$. Helminthol., 22: $277-283$

HeEmstra, P. C., RANDAll, J. E. (1993): Groupers of the world. FAO Fisheries synopsis no. 125, vol. 16. FAO. Rome, 382 pp.

Hinsinger, D. D., Justine, J.-L. (2006): The 'Pseudorhabdosynochus cupatus group' (Monogenea: Diplectanidae) on Epinephelus fasciatus, E. howlandi, E. rivulatus and E. merra (Perciformes: Serranidae) off New Caledonia, with descriptions of Pseudorhabdosynochus cyathus n. sp. and P. calathus n. sp. Syst. Parasitol., 64: $69-90$

JANSEN, P. A., BAKKE, T. A. (1991): Temperature-dependent reproduction and survival of Gyrodactylus salaris Malmberg, 1957 (Platyhelminthes: Monogenea) on Atlantic salmon (Salmo salar L.). Parasitology, 102: 105 - 112

JaCKsON, J. A., Tinsley, R. C., Du PreEz, L. H. (2001): Differentiation of two locally sympatric Protopolystoma (Monogenea: Polystomatidae) species by temperaturedependent larval development and survival. Int. J. Parasitol., 31: $815-821$

Justine, J.-L. (2005): Species of Pseudorhabdosynochus Yamaguti, 1958 (Monogenea, Diplectanidae) from Epinephelus fasciatus and E. merra (Perciformes, Serranidae) off New Caledonia and other parts of the Indo-Pacific Ocean, with a comparison of measurements of specimens prepared with different methods and a description of $P$. caledonicus n. sp. Syst. Parasitol., 62: 1 - 37
Justine, J.-L. (2007): Parasite biodiversity in a coral reef fish: twelve species of monogeneans on the gills of the grouper Epinephelus maculatus (Perciformes: Serranidae) off new Caledonia, with a description of eight new species of Pseudorhabdosynochus (Monogenea: Diplectanidae). Syst. Parasitol., 66: $81-129$

JUSTINE, J.-L. (2008): Diplectanum parvus sp. nov. (Monogenea, Diplectanidae) from Cephalopholis urodeta (Perciformes, Serranidae) off New Caledonia. Acta Parasitol., 53: $127-132$

KABATA, Z. (1985): Parasites and Diseases of Fish Cultured in the Tropics. Taylor and Francis Ltd, 318 pp.

KEARN, G. C. (1994): Evolutionary expansion of the Monogenea. Int. J. Parasitol., 24: 1227 - 1271

KING, T. A., CABLE, J. (2007): Experimental infections of the monogenean Gyrodactylus turnbulli indicate that it is not a strict specialist. Int. J. Parasitol., 37: $663-672$

Koskivaara, M., Valtonene, E. T., Prost, M. (1991): Seasonal occurrence of gyrodactylid monogeneans on the roach (Rutilus rutilus) and variations between four lakes of differing water quality in Finland. Aqua. Fennica., 21: $47-$ 55

KOSKIVAARA, M. (1992): Environmental factors affecting monogeneans parasitic on freshwater fishes. Parasitol. Today, 8: $339-342$

KRITSKY, D. C., BEVERlEY-Burton, M. (1986): The status of Pseudorhabdosynochus Yamaguti, 1958, and Cycloplectanum Oliver, 1968 (Monogenea: Diplectanidae). Proc. Biol. Soc. Wash., 99: $17-20$

LEGENDRE, L., LEGENDRE, P. (1983): Numerical ecology. Elsevier Scientific Publishing Company, Amsterdam Oxford, New York

LEONG, T. S., Wong, S. Y. (1990): Parasites of healthy and diseased juvenile grouper (Epinephelus malabaricus Bloch \& Schneider) and seabass (Lates calcarifer Bloch) in floating cages in Penang, Malaysia. Asian Fish Sci., 3: 319 $-327$

LEONG, T. S. (1994): Parasites and diseases of cultured marine finfishes in Southeast Asia. PhD thesis, Penang: University Sains Malaysia

LEONG, T. S. (1997): Control of parasites in cultured marine finfishes in Southeast Asia - an overview. Int. J. Parasitol., 27: 1177 - 1184

LiaO, I. C., Su H. M., Chang E. Y. (2001): Techniques in finfish larviculture in Taiwan. Aquaculture, 200: 1-31

LYMBERY, A. J. (1989): Host specificity, host range and host preference. Parasitol. Today, 5: $298-298$

Margolis, L., Esch, G. W., Holmes, J. C., Kuris, A. M., SCHAD, G. A. (1982): The use of ecological terms in parasitology. J. Parasitol., 68: 131 - 133

Mo, T. A. (1992): Seasonal variations in the prevalence and infection intensity of Gyrodactylus salaris Malmberg, 1957 (Monogenea: Gyrodactylidae) on Atlantic salmon parr, Salmo salar (L.), in the River Batnfjordselva, Norway. J. Fish Biol., 41: 697 - 707

Mo, T. A. (1997): Seasonal occurrence of Gyrodactylus derjavini (Monogenea) on brown trout, Salmo trutta, and Atlantic salmon, Salmo salar, in the Sandvikselva River, 
Norway. J. Parasitol., 83: 1025 - 1029

Moen, D. S., StockWell, C. A. (2006): Specificity of the monogenean Gyrodactylus tularosae Kritsky and Stockwell, 2005, to its natural host, the white sands pupfish (Cyprinodon tularosa Miller \& Echelle 1975). Comp. Parasitol., 73: 278 - 281

Nagasawa, K., Cruz-Lacierda, E. R. (2004): Diseases of cultured groupers. Southeast Asian Fisheries Development Center, Aquaculture Department, Iloilo, Philippines, $81 \mathrm{pp}$.

NAsh, G., Erson, I. G., Shariff, M., Shamsudin, M. N. (1987): Bacteriosis associated with epizootic in the giant sea perch, Lates calcarifer, and the estuarine grouper, Epinephelus tauvina, cage cultured in Malaysia. Aquaculture, 67: $105-111$

Olstad, K., Robertsen, G., Bachmann, L., Bakke, T. A. (2007): Variation in host preference within Gyrodactylus salaris (Monogenea): an experimental approach. Parasitology, 134: 589 - 597

ÖTÜRK, M. O., Altunel, F. N. (2006): Occurrence of Dactylogyrus infection linked to seasonal changes and host fish size on four cyprinid fishes in Lake Manyas, Turkey. Acta Zool. Acad. Sci. Hung., 52: 407 - 415

POJMAŃSKA, T. (1994): Infection of common carp, and three introduced herbivorous fish from Żabieniec fish farm, in relation to their sizes. Acta Parasitol. Polonica, 39: $16-24$

Poulin, R. (1992): Determinants of host-specificity in parasites of freshwater fishes. Int. J. Parasitol., 22: 753 - 758 RAwson, M. V., Rogers, W. A. (1973): Seasonal occurrence of Gyrodactylus macrochiri Hoffman \& Putz, 1964 on bluegill and largemouth bass. J. Wildl. Dis., 9: $174-177$

ScotT, M. E., Anderson, R. M. (1984): The population dynamics of Gyrodactylus bullatarudis (Monogenea) within laboratory populations of the fish host Poecilia reticulata. Parasitology, 89: 159 - 194

ScOTT, M. E., NoKES, D. J. (1984): Temperature dependent reproduction and survival of Gyrodactylus bullatarudis (Monogenea) on guppies (Poecilia reticulata). Parasitology, 89: $221-227$

Soleng, A., BAKKe, T. A. (1998): The susceptibility of three-spined stickleback (Gasterosteus aculeatus), ninespined stickleback (Pungitius pungitius), and flounder
(Platichthys flesus) to experimental infections of Gyrodactylus salaris Malmberg (Monogenea).Folia parasitol., 45: $270-274$

Soleng, A., BAKke, T. A. (2001): The susceptibility of grayling (Thymallus thymallus) to experimental infections with the monogenean Gyrodactylus salaris. Int. J. Parasitol., 31: $793-797$

VAn Damme, P. A., Ollevier, F. (1994): Infection dynamics of Lernaeocera lusci on sand goby Pomatoschistus minutus in the Oosterschelde (The Netherlands). Dis. Aquat. Org., 19: $83-87$

West, A. P., Roubal, F. R. (1998): Population dynamics of the monogenean Anoplodiscus cirrusspiralis on the snapper, Pagrus auratus. Int. J. Parasitol., 28: 571 - 577 Whittington, I. D., Horton, M. A. (1996): A revision of Neobenedenia Yamaguti, 1963 (Monogenean: Capsalidae) including a redescription of $N$. melleni (macCallum 1927) Yamaguti, 1963. J. Hat. Hist., 30: 1113 - 1156

Winger, A. C., Marte, K., RoAR, K., Rune, K. (2008): Seasonal dynamics and persistence of Gyrodactylus salaris in two riverine anadromous Arctic charr populations. Environ. Biol. Fish, 83: $117-123$

YAMAGUTI, S. (1953): Parasitic worms mainly from Celebes. Part 2. Monogenetic trematodes of fishes. Acta Med. Okayama, 8: 203 - 256

YANG, T. B., ZENG, B. J., GIBSON, I. D. (2005): Description of Pseudorhabdosynochus shenzhenensis n. sp. and redescription of P. serrani (Yamaguti, 1953) from Epinephelus coioides (Harmilton) off Dapeng Bay, Shenzhen, China. J. Parasitol., 91: $808-813$

YANG, T. B., LIU, J. F., GIBSON, D. I., AN, D. (2006): Spatial distributions of two species of monogeneans on the gills of Siganus fuscescens (Houttouyn) and their seasonal dynamics in caged versus wild-caught hosts. J. Parasitol., 92: $933-940$

Yuki, K., IKUO, T., TOYOHIKo, N., MAMORU, Y. (2008): A mixed infection in sevenband grouper Epinephelus septemfasciatus affected with viral nervous necrosis (VNN). Aquaculture, 284: 41 - 45

ZENG, B. J. (2006): The fauna and population dynamics of monogeneans from Epinephelus spp. in Daya Bay, South China Sea. PhD thesis, China: Zhongshan University, $257 \mathrm{pp}$. 